\title{
The Influence of Partner Relationship Quality on Fertility
}

\section{L'influence de la qualité de la relation avec le partenaire sur la fécondité}

\author{
Arieke J. Rijken · Aart C. Liefbroer
}

Received: 15 May 2007 / Accepted: 29 January 2008/Published online: 15 February 2008

(C) The Author(s) 2008

\begin{abstract}
This study examines whether partner relationship quality influences fertility, and if so, in which direction and which aspects of relationship quality are relevant. Competing hypotheses are tested. One hypothesis assumes that higher relationship quality leads to higher rates of childbearing, as a high-quality relationship offers the most favourable environment to raise children. An opposite hypothesis expects that lower relationship quality leads to higher rates of childbearing, as couples might have children in order to improve their relationship. Hazard analyses are performed using three waves of the Panel Study on Social Integration in the Netherlands. Findings indicate that positive as well as negative interaction between partners has a negative effect on first- and higher-order birth rates. This suggests that couples are most likely to have children if they do not have too much negative interaction, but neither interact in a very positive way. Value consensus negatively influences higher-order birth rates.
\end{abstract}

Keywords Fertility - Panel study · Relationship quality · The Netherlands

Résumé Cette étude examine l'influence de la qualité de la relation avec le partenaire sur la fécondité, et cherche à identifier les aspects de la relation les plus pertinents par rapport à cette question. Différentes hypothèses sont explorées. La

\footnotetext{
A. J. Rijken $(\bowtie)$

Department of Interdisciplinary Social Science, Utrecht University, Heidelberglaan 2, 3584 CS Utrecht, The Netherlands

e-mail: A.J.Rijken@uu.nl
}

\section{A. C. Liefbroer}

Department of Social Demography, Netherlands Interdisciplinary Demographic Institute (NIDI), Postbus 11650, 2502 AR The Hague, The Netherlands

e-mail: liefbroer@nidi.nl

\section{A. C. Liefbroer}

Department of Social Research Methodology, Vrije Universiteit, Amsterdam, The Netherlands 
première postule que plus la qualité de la relation est bonne, plus la fécondité est élevée, car une relation de bonne qualité offre le contexte le plus favorable pour élever des enfants. A l'opposé, une deuxième hypothèse postule que plus la qualité de la relation est mauvaise, plus la fécondité est élevée, car les couples pourraient avoir des enfants pour améliorer leur relation. Des modèles de durée sont utilisés pour analyser les trois vagues du Panel d'Etude de l'Intégration Sociale aux PaysBas. Il apparaît que les interactions positives, de même que les interactions négatives entre partenaires ont une influence négative sur les naissances de rang 1 et sur les suivantes. Ce résultat suggère que les couples ont le plus de chances d'avoir des enfants s'ils ont des interactions qui ne sont ni trop bonnes, ni trop mauvaises. L'accord entre partenaires au niveau du système de valeurs influence de façon négative les naissances de rang supérieur.

Mots-clés fécondité - étude de panel · qualité de la relation · Pays-Bas

\section{Introduction}

Most of the fertility literature studies the influence of individual characteristics, mostly women's, on the timing and quantum of childbearing. However, the great majority of children are born within couple relationships. Hence, it is important that the influence of characteristics of the couple on fertility decisions is studied as well. Indeed, in recent years increasing attention has been paid to the influence of characteristics of both partners and to couple characteristics (Coombs and Chang 1981; Corijn et al. 1996; Jansen and Liefbroer 2006; Morgan 1985; Thomson 1997, 2002; Thomson and Hoem 1998; Thomson et al. 1990). Nevertheless, as yet little attention has been paid to the question to what extent fertility is influenced by the quality of the partner relationship itself. The literature that does pay attention to it focuses almost exclusively on one specific aspect of relationship quality, namely union stability (Koo and Janowitz 1983; Lillard and Waite 1993; Myers 1997; Thomson and Henz 2005; Wu 1996). Yet, a vast social-psychological literature shows that marital quality is a multidimensional phenomenon. Besides perceived stability, it includes other evaluative dimensions such as relationship satisfaction, behavioural dimensions like disagreement and interaction (Johnson et al. 1986; Glenn 1990), and value consensus (Spanier 1976).

Although it is likely that relationship quality influences fertility decisions, it is unclear whether its influence is positive or negative. Couples with a high-quality relationship might be more likely to have children, because their relationship constitutes a favourable environment to raise a child (Myers 1997) and because they are more willing to make the major joint investment that having children implies (Lillard and Waite 1993). However, couples in a low-quality relationship might want to have a child in order to revitalize their union. The aim of this article is to contribute to the explanation of fertility behaviour by addressing the question whether the quality of the partner relationship influences the timing of fertility, and if so, what aspects of relationship quality are of particular relevance. This latter question is explorative. 
We expand on the existing literature in several ways. First, we take the multidimensionality of relationship quality into account. We argue that one should not only study the influence of relationship stability on fertility, but that other aspects of relationship quality may also be relevant in making fertility decisions. Second, unlike most studies that focus on the effect of marital stability-with the exception of a study by Myers (1997)—we use direct measures of separation proneness as well as of other aspects of relationship quality. Third, we examine whether relationship quality has the same influence on the timing of entry into parenthood as on the timing of second and third births. Finally, we study the effect of relationship quality on the likelihood of births both within marriage and within unmarried cohabitation. Attention to childbearing within non-marital unions is important because many children are born within such unions throughout the Western world. In addition, the choice to get married may not be independent of the choice to have children (Baizán et al. 2003, 2004). Rather, the desire to have children might be an important reason to get married for cohabiting couples. In these circumstances, restricting the analysis to married couples could lead to biases in assessing the influence of relationship quality on fertility.

To answer our research question, we conduct event history analyses using panel data from the 1987, 1991 and 1995 waves of the Panel Study of Social Integration in the Netherlands (PSIN). Studying the relationship between fertility and relationship quality in the Netherlands is particularly interesting because it is a country with liberal family values (Inglehart and Baker 2000). In such a context, neither the continuity of partner relationships nor the decision to have children can be taken for granted, but is thought to be negotiated upon by the partners involved (Giddens 1991).

\section{Theory and Previous Studies}

Whereas an extensive literature exists on the expected consequences of having children for the quality of the relationship between partners (Callan 1985, 1986; Fawcett 1988; Bulatao 1981; Miller and Pasta 1994) and on its real consequences for relationship quality (Glenn 1989; Helms-Erickson 2001; Kurdek 1999) and stability (Cherlin 1977; Lillard and Waite 1993; Waite and Lillard 1991), theory and research on the opposite influence of relationship quality on fertility is relatively scarce. Moreover, most studies that address the issue focus almost exclusively on the influence of union stability. We start with reviewing this latter literature and subsequently discuss the reasons for broadening the scope to include a diversity of aspects of relationship quality.

In the literature on the influence of union stability on childbearing, two opposing hypotheses are proposed. The first hypothesis suggests that higher perceived union stability leads to earlier childbearing. This position is advocated by Lillard and Waite (1993), who emphasized that children represent the largest investment in marriage and that, therefore, the presence of children (especially young children) raises the costs of dissolution. A dissolution could imply either having to raise the children alone or to have reduced or no contact with the children. Lillard and Waite 
assumed that people take these costs into account in fertility decision making. Therefore, they hypothesized that the higher the potential instability of the marriage, the lower the likelihood of a marital conception. It has to be noted that in earlier articles (e.g. Cohen and Sweet 1974; Thornton 1977, 1978) it was already suggested that marital discord would reduce fertility not only by reduced exposure in case of dissolution, but also prior to dissolution by reduced intercourse and by motivated prevention of conception.

The opposite hypothesis (union instability leads to earlier childbearing) is proposed by Friedman et al. (1994), who developed what they call an "alternative" rational choice theory of fertility: the uncertainty reduction theory of parenthood. This theory postulates that the value of having children in developed societies, where children's net instrumental value is negative, lies in uncertainty reduction. This theory assumes that rational actors will always seek to reduce uncertainty, among others by enhancing their marital solidarity. This latter aspect of their theory is relevant for our study. Having children is supposed to enhance marital solidarity, because it increases marital capital (Becker et al. 1977). Consequently, Friedman et al. derived the hypothesis that the risk of divorce has a positive effect on the propensity to parenthood. They also expected that the multistranded quality of the relationship_-financial ties, ties of common interest-between husbands and wives has a negative effect on the propensity to parenthood, because partners who are already very involved with each other have less need to revert to having children as a strategy to cement the relationship.

Relatively few empirical studies have tested these opposite hypotheses. Lillard and Waite (1993) modelled the hazard of union disruption and the hazard of marital conception simultaneously, and included the estimated hazard of disruption as a predictor in the equation to estimate the hazard of marital conception. They found that the risk of marital disruption faced by a married woman has a negative effect on her likelihood of marital childbearing: it lengthens the intervals between births and decreases the chances that a child will be born. Thornton's (1978) finding that married women had reduced fertility during the 2 years just before separation also suggests that the risk of a marital disruption decreases childbearing. Koo and Janowitz (1983) tried to disentangle the effects of childbearing on marital discord (indicated by actual separation) and vice versa by applying a simultaneous logit model. They conducted separate analyses for different marriage intervals and found that marital discord did not have a statistically significant effect on fertility until late in marriage. Conjugal discord only increased the likelihood that couples had a(nother) child if these marriages lasted more than 12 years. A drawback of all of these studies is that no direct measures of the perceived risk of marital disruption were used.

The theoretical article on the uncertainty reduction theory of parenthood by Friedman et al. (1994) has generated some empirical studies. One of these (Wu 1996) focused on the role of general life uncertainty on childbearing within cohabitational relationships but did not include a direct measure of relationship uncertainty. To our knowledge, the study of Myers (1997) on marital uncertainty and childbearing is the only one that included direct measures of divorce proneness, marital happiness and marital interaction (how often partners engage jointly in five 
different activities). Myers found that divorce proneness negatively influences childbearing for all parities and that marital happiness positively influences childbearing at higher-order parities.

All of these studies focus on the influence of (perceived) union stability on the timing of childbearing. However, union stability can be considered as an aspect of the broader concept of relationship quality (Johnson et al. 1986), and it is questionable whether it is the only or even the most important aspect in deciding on having children. One could easily imagine that people, even if they are not considering leaving their partner or are not afraid of being left, still take aspects of the quality of the partner relationship into account in making childbearing decisions. People whose relationship quality is relatively low might consider their partner relationship not (yet) suitable for having children, but still rather stay together with their partner than be alone. Or, conversely, such people might want to strengthen the bond with their partner by having a child. Hence, a logical extension of the hypotheses on union stability would be to juxtapose two general hypotheses on the effect of relationship quality on fertility behaviour. One hypothesis would assume that couples prefer to have children within a high-quality relationship, as this offers the most favourable environment to raise a child. Besides, partners in a high-quality relationship may be more likely to make the investment that having children implies. This hypothesis (Hypothesis 1) expects that higher relationship quality leads to higher rates of childbearing. We call this the 'favourable environment' hypothesis, as a high-quality relationship offers a favourable environment to have and raise children. A competing hypothesis would assume that couples decide to have children in order to cement their low-quality relationship. This hypothesis (Hypothesis 2) expects that lower relationship quality leads to higher rates of childbearing. We call this the 'revitalization' hypothesis, as having a child is viewed as a means to revitalizing one's relationship.

Another issue is whether the influence of relationship quality on fertility timing is the same for first and for higher-order births. Lillard and Waite (1993) argued that childless people may be especially sensitive to the potential stability of their marriage in deciding to become parents. The costs of a disruption appear to rise dramatically with the birth of the first child. In addition, Bulatao (1981) observed that people expect that the birth of a first child will have stronger consequences for their partner relationship than the birth of subsequent children. Thus, relationship quality might have a stronger effect on the timing of first births than on the timing of subsequent births. Conversely, one could also argue that the effect of relationship quality may be stronger for subsequent births than for first births, because childless people may want to become parents anyway, regardless of the fate of their relationship (Lillard and Waite 1993). In order to examine this issue, separate models for having a first birth and for having a higher-order birth will be estimated.

Above, the concept of relationship quality has been used rather loosely. However, a review of marriage literature in the United States suggests a wide variability in the definition and operationalization of marital quality (Xu 1998). According to the so-called "individual feelings school" (Glenn 1990), marital quality should be treated as a global evaluation of the marriage, which makes it a subjective and unidimensional concept (Norton 1983). Such a stand contrasts with 
the "multidimensional school", according to which it is ambiguous to blend several dimensions, such as positive and negative dimensions, in one scale (Johnson et al. 1986). Besides, the adherents of this school argue that it is important to include objective evaluations, such as assessing the frequencies of marital disagreements (Xu 1998).

Following this multidimensional approach, we consider relationship quality as a concept that includes both evaluative aspects (satisfaction or happiness, perceived stability) and behavioural aspects (what partners actually do together) (Amato et al. 2003). An important issue is which aspects of relationship quality might be related to fertility timing. The literature on perceived union stability stresses the importance of evaluative aspects. If people think that their union is at risk, or will be at some time in the future, they will adjust their fertility behaviour by either trying to have a baby soon (Friedman et al. 1994) or by postponing childbearing (Lillard and Waite 1993). Alternatively, one could argue that couples make decisions about childbearing not so much on the basis of expectations about the (future) stability of their relationship, but rather on the basis of current experiences. In that case, it might be aspects like the kind of interaction patterns and the degree of value consensus that are important. To examine this issue, we include several relationship quality aspects in our study.

\section{Method}

\subsection{Data}

The data used in this study are from the PSIN (Liefbroer and Kalmijn 1997). This study consists of six waves of data collection (1987-2006) among a sample of Dutch young adults. In Waves 1 and 3, extensive information on relationship quality was collected. Therefore, this study uses data on relationship quality and other independent variables from Waves 1 and 3 and data on actual childbearing from Waves 1, 3 and 4. These waves took place in 1987, 1991 and 1995. Data were collected using a combination of face-to-face interviews and additional selfadministered questionnaires. In 1987, a random sample of Dutch men and women born in 1961, 1965 and 1969 was drawn. The sample was stratified according to birth cohort and gender, using municipal population registers as the sampling frame. A total of 1,775 interviews were conducted in Wave 1. The response rate was $63.4 \%$, which is a high for the Netherlands, where survey response rates tend to be lower than in other countries (De Leeuw and De Heer 2001). In Wave 3, $70.9 \%$ of the original sample and in Wave $4,54.2 \%$ of the original sample participated.

For this study, we selected respondents who were cohabiting (unmarried or married) at the time of Wave 1 and/or Wave 3. Separate analyses were conducted for first births and for second and third births. The sample for analyses of first births includes 451 respondents and the sample for analyses of additional births includes 218 respondents. The respondents were between 18 and 26-year old at the time of Wave 1 , and between 26 and 34 at the time of Wave 4 . 


\subsection{Variables}

Information on the year and month of birth of all biological children was obtained in the Wave 1 and updated in all subsequent waves. The time of conception leading to a birth, located at 9 months before the actual birth, was used as the indicator of the timing of fertility.

The concept of relationship quality is operationalized in a multidimensional way by distinguishing four dimensions: positive interaction, negative interaction, value consensus and separation proneness. The positive interaction scale contains four items: "Does your partner look at you when he or she talks to you?", "Do you often talk about common interests?", "Does your partner show understanding?", and "How often do you and your partner talk about nice things that happened during the day?" The negative interaction scale is also formed by four items: "How often does your partner sulk?", "Does your partner sometimes talk to you with an unpleasant voice?", "We quarrel" and "How often does your partner find fault with you?" The responses were scored on a five-point scale ranging from 1 (not at all) to 5 (very often) and were summed and recoded into a scale ranging from 0 to 10 . These items are previously used by Buunk and Nijskens (1980), among others. Alpha coefficients of the positive interaction scale are .62 in Wave 1 and .68 in Wave 3. Alpha coefficients of the negative interaction scale are .60 in Wave 1 and .69 in Wave 3. Although the alpha coefficients are not high, they can still be considered sufficient, given that each scale consists of only four items. In order to examine whether positive and negative interaction should be considered as two different scales or whether one factor underlies the items, we conducted factor analyses with orthogonal and oblique rotation. They showed that a two-factor solution is highly preferable over a one-factor solution.

To examine whether it is reasonable to include positive and negative interaction, which both have highly skewed distributions, as continuous variables, we also categorized these variables. We first recoded each variable into a low, medium and high category, each including about one third of the respondents. On the basis of preliminary analyses (results not shown), we decided to dichotomize the variables as follows: The scores of the low group on positive interaction (scores up to and including 7.5 on a $0-10$ scale) were recoded into 1 and the medium and high scores were recoded into 0 , resulting in the variable 'low positive interaction'. For negative interaction the scores of the high group (scores 3.75 and above on a scale $0-10$ scale) were recoded into 1 and the remaining scores were recoded into 0 , resulting in the variable 'high negative interaction'.

Value consensus was measured with two items: "How often do you agree or disagree with your partner on opinions on general norms and values?" and "How often do you agree or disagree with your partner on outlook on life?" Answers were scored on a seven-point scale ranging from 1 (always disagreeing) to 7 (always agreeing). They were summed and recoded into a scale ranging from 0 to 10 . The correlation between these two items is .36 in Wave 1 and .40 in Wave 3. These items come from the dyadic consensus subscale of the Dyadic Adjustment Scale (Spanier 1976). Although it would have been preferable to use multiple indicators for separation proneness, the data only provide one item, which is formulated as "I 
consider leaving my partner". Answers were coded on a five-point scale ranging from 1 (not at all) to 5 (very often).

Literature on fertility shows that age, education and religiosity are important factors determining fertility behaviour (e.g. Blossfeld 1995; Corijn et al. 1996). Therefore, we included these characteristics, from both partners if data permitted, as control variables. We included age at the start of cohabitation for the analyses of first childbirth and age at the time of previous childbirth for the analyses of higher-order childbirths. We used respondent's and partner's age in months and transformed these variables into men's and women's age. Educational level was measured for the respondents as well as their partners. We transformed this information into men's educational level and women's educational level. We used highest educational level attained or level of current education, if the respondent or partner was still enrolled in education at the moment of the interview and the level of current education was higher than the highest level previously attained. Level of education is coded as the number of years of schooling after primary school that are required to finish this level (range 0-11). Denominational attachment was measured on a six-point scale. The score 0 implies that the respondent is no church member, and if the respondent is a church member, the scores 1-5 represent the degree to which they feel attached to their church $(1=$ not at all, $5=$ very strong). In Wave 1 , no questions were asked with regard to the partner's religiosity, hence we only included the respondent's denominational attachment. The gender of the respondent is included as a control variable $(0=$ male, $1=$ female $)$, because the relationship quality measures are based on information reported by the respondent and because some of the background characteristics are only known for the respondent and not for the partner.

Parenthood intentions are also known to strongly influence fertility behaviour (Schoen et al. 1999; Thomson 1997). They were measured with the question: "Do you intend to have (more) children in the future?" In Wave 1 answers were scored on a five-point scale ranging from 1 (certainly not) to 5 (certainly yes); in Wave 3 the answers were scored on a seven-point scale, which was recoded to a five-point scale. We only included the respondent's parenthood intentions, because in Wave 1 no questions were asked about the partner's parenthood intentions. Furthermore, a marital status dummy was included, indicating whether the partners were married or not at the time of the interview $(0=$ not married, $1=$ married $)$, because we expect married couples to have children sooner than cohabiting couples. The duration of the relationship before the start of cohabitation was included as a control variable in the model of first birth, because couples who have been dating longer before they start living together have more information about the quality of their match, and thus might have a first child sooner than couples who start cohabiting early in their relationship. Finally, the number of children a respondent has (one or two) was included in the model of second and third birth.

\subsection{Method of Analysis}

To examine the effect of relationship quality on the timing of childbirth, a series of Cox regression hazard rate models was estimated with the hazard of conception 
resulting in a life birth as the dependent variable. A hazard rate represents the risk that a person will experience an event, given that this person has not yet experienced the event. People were at risk from the time of the interview until the event (conception) occurred. If they separated or divorced before the event, they were censored at the time of separation or divorce. If they did not experience a birth nor a union dissolution before the next interview, they were censored at 9 months before the next interview, because it is not always known whether the respondent or the partner of the respondent is pregnant at the next interview. In the analyses of first birth rates, time is measured in months since the start of cohabitation, and in the analyses of second and third birth rates, time is measured in months since the birth of the previous child. We created person records for the intervals between Wave 1 and Wave 3 and between Wave 3 and Wave 4. Respondents who participated in Waves 1, 3 and 4, and were cohabiting at the time of Waves 1 and 3, contribute two person-records, irrespective of whether they had the same partner or different partners at the time of Wave 1 and Wave 3. Hence, the observations are not all independent but nested in persons. Therefore, we estimated robust parameters, using the cluster option in Stata (StataCorp 2005) to adjust the standard errors for intraperson correlation. Separate models were estimated for having a first birth and having a subsequent birth. If respondents had two or more births between two waves, the second and subsequent births are not included in the analyses, since the relationship quality might have changed after the first birth.

The characteristics of the samples for the analyses of first births and for the analyses of subsequent births are presented in Table 1. The total number of observations in the analyses of first births is 551, representing 451 respondents, and 258 first births occurred. The average duration of observation is 2.5 years. The number of observations for the analyses of second and third births was 268, representing 218 respondents. A total of 120 second and third births occurred and the average duration of observation is 2.7 years. Means and standard deviations of the control variables are also shown in Table 1. All analyses were performed using the Stcox procedure in Stata.

\section{Results}

\subsection{Main Results}

We start with a description of the relationship quality variables. The means and standard deviations of these variables are presented in Table 2. Not surprisingly, it appears that, overall, reports on the quality of the relationship are positive: average scores on positive interaction are high, scores on negative interaction and separation proneness are low. Average value consensus is lower than positive interaction, but still moderately high. There are hardly any differences on relationship quality variables between the sample of childless couples and the sample of couples that already have at least one child, yet less positive interaction with the partner is reported by respondents who already have a child. This is in line with results of studies on the effect of having children on marital quality (e.g. Carlson 2007; Glenn 
Table 1 Descriptive characteristics of the samples

\begin{tabular}{|c|c|c|c|c|c|}
\hline & \multicolumn{2}{|c|}{$\begin{array}{l}\text { Sample for analyses of first } \\
\text { childbirth }\end{array}$} & \multicolumn{3}{|c|}{$\begin{array}{l}\text { Sample for analyses of second and } \\
\text { third childbirth }\end{array}$} \\
\hline Number of observations & 551 & & 268 & & \\
\hline Number of respondents & 451 & & 218 & & \\
\hline Number of births & 258 & & 120 & & \\
\hline Average duration of observation ${ }^{\mathrm{a}}$ & 2.50 & & 2.67 & & \\
\hline \multicolumn{2}{|l|}{ Control variables } & $M /$ proportion & SD & $M /$ proportion & SD \\
\hline \multicolumn{2}{|l|}{ Age woman at start cohabitation ${ }^{\mathrm{a}}$} & 22.33 & 2.75 & & \\
\hline \multicolumn{2}{|l|}{ Age man at start cohabitation ${ }^{\mathrm{a}}$} & 24.25 & 2.92 & & \\
\hline \multicolumn{3}{|l|}{ Age woman at birth previous child ${ }^{\mathrm{a}}$} & & 25.75 & 2.75 \\
\hline \multicolumn{3}{|l|}{ Age man at birth previous child ${ }^{\mathrm{a}}$} & & 28.50 & 3.83 \\
\hline \multicolumn{2}{|l|}{ Gender respondent ${ }^{\mathrm{b}}$} & .46 & & .33 & \\
\hline \multicolumn{2}{|l|}{ Education woman ${ }^{c}$} & 5.9 & 2.3 & 4.8 & 2.3 \\
\hline \multicolumn{2}{|c|}{ Education $\operatorname{man}^{\mathrm{c}}$} & 6.1 & 2.6 & 5.3 & 2.6 \\
\hline \multicolumn{2}{|c|}{ Denominational attachment respondent ${ }^{\mathrm{d}}$} & 1.1 & 1.4 & 1.4 & 1.7 \\
\hline \multicolumn{2}{|c|}{ Parenthood intentions respondent $\mathrm{e}^{\mathrm{e}}$} & 4.2 & 1.1 & 3.2 & 1.5 \\
\hline \multicolumn{2}{|c|}{ Relationship duration before cohabitation $^{\mathrm{a}}$} & 2.97 & 1.95 & & \\
\hline \multicolumn{2}{|c|}{ Marital status ${ }^{\mathrm{f}}$} & .19 & & .74 & \\
\hline \multicolumn{2}{|l|}{ Number of children } & & & 1.6 & .5 \\
\hline \multicolumn{6}{|l|}{ a Years } \\
\hline \multicolumn{6}{|l|}{ b $0=$ Male, $1=$ female } \\
\hline \multicolumn{6}{|c|}{ c Years of schooling after primary school } \\
\hline \multicolumn{6}{|c|}{ d Scale: $0-5,{ }^{\mathrm{e}}$ Scale: $1-5$} \\
\hline f $0=$ Not married, $1=$ married & & & & & \\
\hline
\end{tabular}

Panel study on social integration in the Netherlands, Waves 1, 3 and 4 (1987-1995)

and McLanahan 1982), suggesting that the presence of children reduces marital quality.

Table 3 shows the models for the hazard of having a first birth and the hazard of having a second or third birth. Before we discuss the influence of the relationship quality variables on birth rates, we will pay attention to the effects of the control variables. The age of the woman at the start of the cohabitation has a positive influence on the first birth rate, implying that the older the woman is at the start of cohabitation, the sooner the couple has their first child. The age of the woman at the birth of the previous child has a negative influence on the rate of second and third births; the younger the woman is at the birth of the previous child, the sooner she has her next child. A woman's educational attainment has a negative influence on the first birth rate, but when a couple already has children, her educational attainment does not have a statistically significant effect on the rate of subsequent births. The age of the male partner at the start of the union or at the time of the previous birth and his educational attainment do not have an effect on the rate of 
Table 2 Description of relationship quality variables

\begin{tabular}{|c|c|c|c|c|}
\hline \multirow[t]{2}{*}{ Relationship quality variables } & \multicolumn{2}{|c|}{$\begin{array}{l}\text { Sample for analyses of first } \\
\text { childbirth }(N=551)\end{array}$} & \multicolumn{2}{|c|}{$\begin{array}{l}\text { Sample for analyses of second and third } \\
\text { childbirth }(N=268)\end{array}$} \\
\hline & $M$ & SD & $M /$ proportion & SD \\
\hline Positive interaction $^{a}$ & 8.6 & 1.2 & 8.3 & 1.3 \\
\hline Low positive interaction ${ }^{b}$ & & & .36 & \\
\hline Negative interaction $^{\mathrm{a}}$ & 2.9 & 1.4 & 2.9 & 1.3 \\
\hline High negative interaction $^{c}$ & & & .30 & \\
\hline Value consensus $^{\mathrm{a}}$ & 7.2 & 1.2 & 7.3 & 1.0 \\
\hline Separation proneness ${ }^{\mathrm{d}}$ & 1.1 & .4 & 1.1 & .3 \\
\hline
\end{tabular}

a Scale: 0-10

${ }^{\mathrm{b}} 0=$ Medium or high positive interaction, $1=$ low positive interaction

c $0=$ Medium or low negative interaction, $1=$ high negative interaction

d Scale: 1-5

Panel study on social integration in the Netherlands, Waves 1, 3 and 4 (1987-1995)

Table 3 Risk estimates for hazard model of first childbirth $(N=551)$ and hazard model of second and third childbirth $(N=268)$

\begin{tabular}{|c|c|c|c|c|}
\hline \multirow[t]{2}{*}{ Variable } & \multicolumn{2}{|l|}{ First childbirth } & \multicolumn{2}{|c|}{ Second and third childbirth } \\
\hline & $B$ & Robust SE & $B$ & Robust SE \\
\hline Age woman at start cohabitation ${ }^{\mathrm{a}}$ & $.008 * * *$ & .002 & & \\
\hline Age man at start cohabitation ${ }^{\mathrm{a}}$ & .001 & .002 & & \\
\hline Age woman at birth previous child ${ }^{\mathrm{a}}$ & & & $-.009 *$ & .004 \\
\hline Age man at birth previous child ${ }^{\mathrm{a}}$ & & & .002 & .003 \\
\hline Gender respondent ${ }^{\mathrm{b}}$ & .123 & .125 & .175 & .232 \\
\hline Educational attainment woman & $-.103 * * *$ & .029 & .040 & .048 \\
\hline Educational attainment man & .042 & .027 & .008 & .042 \\
\hline Denominational attachment respondent & .059 & .047 & .102 & .063 \\
\hline Parenthood intentions respondent & $.700 * * *$ & .086 & $.787 * * *$ & .110 \\
\hline Relationship duration before cohabitation & $.005 *$ & .086 & & \\
\hline Marital status ${ }^{c}$ & -.170 & .186 & .155 & .225 \\
\hline Number of children & & & $-.666^{*}$ & .262 \\
\hline Positive interaction & $-.173 * *$ & .057 & $-.204 *$ & .089 \\
\hline Negative interaction & $-.146 * *$ & .054 & $-.214 * *$ & .074 \\
\hline Value consensus & -.038 & .063 & -.160 & .116 \\
\hline Separation proneness & .131 & .241 & .163 & .141 \\
\hline Log pseudolikelihood & -1207.2 & & -490.5 & \\
\hline
\end{tabular}

\footnotetext{
${ }^{a}$ Months

b $0=$ Male, $1=$ female

c $0=$ Not married, $1=$ married

$* p<.05, * * p<.01, * * * p<.001$
}

Panel study on social integration in the Netherlands, Waves 1, 3 and 4 (1987-1995) 
first nor of subsequent births. The same is true for the respondent's gender and the respondent's denominational attachment. The duration of the relationship before the start of cohabitation has a positive effect on the first birth rate. The longer a couple has been dating before they start living together, the sooner they have a first child.

Not surprisingly, the respondent's parenthood intentions have a large effect on the rates of first and subsequent childbearing. The stronger the parenthood intentions, the higher the rate of having a first as well as of having a subsequent birth. Whether the couple is married or cohabiting unmarried at the time of the interview does not influence the first birth rate, nor the rate of subsequent births. Parity has a statistically significant negative influence on the rate of subsequent births, indicating that the likelihood of having a second child is higher than the likelihood of having a third child.

Next, we turn to the effects of relationship quality indicators, to answer our questions whether relationship quality influences the timing of childbearing, and if so, which aspects of relationship quality have an effect and in what direction. Table 3 shows that negative interaction negatively influences the rates of first as well as subsequent childbearing. This implies that the more negative interaction occurs within a partner relationship, the more childbearing is postponed. This finding supports the favourable environment hypothesis that relationship quality positively influences childbearing. However, positive interaction also has a statistically significant negative influence on the rates of first and subsequent childbearing, implying that the more positive interaction occurs within the relationship, the more parenthood is postponed. This finding lends support to the revitalization hypothesis that relationship quality negatively influences childbearing. It is surprising to find negative influences of positive and negative partner interaction at the same time, given that positive and negative interaction correlate moderately negatively with each other $(r=-.24$ in Wave 1 and $r=-.30$ in Wave 3). In other words, the effects are not caused by one group of couples scoring high on positive as well as negative interaction and having high birth rates. Our results do not provide evidence that value consensus or separation proneness influences the rate of first childbirth nor the rate of second and third childbirth.

Finally, we examined whether relationship quality has the same influence on entry into parenthood as on the occurrence of second and third births. The results in Table 3 do not indicate a significant difference, given the magnitudes of the standard errors.

\subsection{Additional Analyses}

A number of additional analyses was conducted to examine the robustness of our findings. First, we examined whether the results changed if parenthood intentions and marital status were removed from our models. These factors were included as control variables in order to reduce the amount of unobserved heterogeneity. However, parenthood intentions and marital status could be considered as rather endogenous to fertility. Therefore, we reran our models without parenthood intentions and marital status as explanatory variables. In the resulting models (not 
presented), the negative effect of positive interaction on first and on higher-order birth rates remains statistically significant and about equal in size, while the negative effect of negative interaction decreases slightly and only maintains significance at the 10 level.

Second, we examined whether the negative effect of positive communication on the rates of first and subsequent births might be spurious. It could be argued that it is not so much a lack of positive communication between partners that leads to higher rates of childbirth, but that traditional gender attitudes lead to a low level of positive communication between partners, and at the same time stimulates childbearing. Couples in which the man is oriented towards work and career, while the woman has a strong homemaker orientation, might not have much common interests to talk about, but are likely to have a higher rate of childbearing. Therefore we included in our models a variable on gender role attitudes of the respondent, measured by the level of agreement with the item: "It is most natural that the man is breadwinner and the woman takes care of the household and the children". Adding this variable to the models does not alter the results (not presented). The effects of positive and negative communication on the rates of first and higher-order births remain the same. In addition, to examine whether the nature of partner interaction matters less for the fertility of traditional couples, we tested whether there are interaction effects of positive interaction and gender role attitudes, respectively negative interaction and gender role attitudes. We did not find any evidence for these interaction effects.

Third, we examined whether our models could be improved by categorizing positive interaction and negative interaction, given the skewed distributions of these variables. We recoded both variables into three ordinal categories, each category containing about one third of the observations, and reran our models (results not presented). The model of first birth did not improve and the results indicated that the assumption of linearity is plausible. Conversely, the model of higher-order childbirth showed that the relationship between positive respectively negative interaction and the hazard of higher-order births is not linear; low positive interaction and high negative interaction are the categories that matter. Medium and high positive interaction did not have statistically significantly different effects, neither did medium and low negative interaction. Consequently, we dichotomized positive and negative interaction and included the dummies for low positive interaction and high negative interaction in the model of second and third childbirth (Table 4). The results indicate that, among couples with at least one child, those with low levels of positive interaction are more likely to have an additional child (soon). Furthermore, the negative influence of high negative interaction on higherorder childbirths indicates that couples are less likely to have an additional child when they have high levels of negative interaction. In addition, while value consensus did not have an effect in our previous models, in this second model of higher-order birth, it has a statistically significant negative effect. This implies that the more value consensus there is among partners who have at least one child, the less likely they are to have an additional child soon. This seems to provide support for the revitalization hypothesis that relationship quality negatively influences childbirth and might be considered in line with the negative effect of positive interaction on higher-order birth rates. 
Table 4 Risk estimates for additional hazard model of second and third childbirth $(N=268)$

\begin{tabular}{|c|c|c|}
\hline Variable & $B$ & Robust SE \\
\hline Age woman at birth previous child ${ }^{\mathrm{a}}$ & $-.009 * *$ & .004 \\
\hline Age man at birth previous child ${ }^{\mathrm{a}}$ & .003 & .003 \\
\hline Gender respondent ${ }^{\mathrm{b}}$ & .102 & .238 \\
\hline Educational attainment woman & .046 & .049 \\
\hline Educational attainment man & -.004 & .041 \\
\hline Denominational attachment respondent & .117 & .067 \\
\hline Parenthood intentions respondent & $.824 * *$ & .115 \\
\hline Marital status ${ }^{c}$ & .104 & .231 \\
\hline Number of children & $-.666^{*}$ & .267 \\
\hline Low positive interaction ${ }^{\mathrm{d}}$ & $.582 *$ & .235 \\
\hline High negative interaction ${ }^{\mathrm{e}}$ & $-.695^{* *}$ & .245 \\
\hline Value consensus & $-.223^{*}$ & .112 \\
\hline Separation proneness & .186 & .144 \\
\hline Log pseudolikelihood & -488.9 & .144 \\
\hline
\end{tabular}

${ }^{\mathrm{a}}$ Months, ${ }^{\mathrm{b}} 0=$ Male, $1=$ female, ${ }^{\mathrm{c}} 0=$ Not married, $1=$ married

${ }^{\mathrm{d}} 0=$ Medium or high positive interaction, $1=$ low positive interaction

e $0=$ Medium or low negative interaction, $1=$ high negative interaction

$* p<.05, * * p<.01$

Panel study on social integration in the Netherlands, Waves 1, 3 and 4 (1987-1995)

As the responses on the separation proneness variables are skewed as well, we also conducted additional analyses with a dichotomized variable for separation proneness. The original five-point scale ranging from not at all to very often was recoded into two categories: one category only containing the answer not at all and the other category containing the four other original answer categories. This did not bring about a statistically significant effect of separation proneness in any of the models nor did it improve any of the models (results not shown).

Finally, we checked whether there are interaction effects between gender of the respondent and positive interaction respectively negative interaction, as the relationship quality indicators are only based on information from the respondent. No interaction effects were found.

\section{Discussion and Conclusion}

The aim of this study was to examine whether the quality of the partner relationship influences the timing of fertility, and if so, which aspects have an effect and in which direction. We formulated two contradicting hypotheses. Do couples with a high-quality relationship have higher birth rates because a good relationship offers a favourable environment to raise children or do couples with a low-quality relationship have higher birth rates because they see having children as a way to revitalize their relationship? The existing literature on this topic has a narrow focus 
on the effect of relation stability. We tried to generate new insights by taking into account the multidimensionality of the concept of relationship quality. Specifically, we examined the effects of the following indicators of relationship quality: separation proneness, positive interaction, negative interaction and value consensus. Our results showed that positive and negative interaction influence the first birth rate as well as the rate of second and third childbirths, but in unexpected ways. The effect of value consensus is less clear-cut. We did not find evidence for influence of separation proneness.

We found that positive as well as negative partner interaction has a negative effect on the timing of first as well as second and third births. These findings, and especially the postponing effect of positive communication, turned out to be robust in a number of additional sensitivity analyses. They lend support to both of our competing hypotheses. How can we reconcile these results? We would suggest that they indicate that reality is more complicated than either one of our contradicting hypotheses suggests. On the one hand, the more negative interaction is going on in a couple relationship, the more likely it is that this couple will postpone childbearing, suggesting that not having a bad relationship constitutes a pre-condition for having children. On the other hand, experiencing a lot of positive partner interaction seems to lead to the postponement of childbearing as well. This suggests that couples with low levels of positive interaction might opt for a(nother) child to revitalize their relationship. At the same time, it might imply that if a great deal of positive interaction is going on, partners are happy with their current family situation and view a(n) (additional) child as a potential threat to this happiness. Taken together, these results seem to suggest that couples are particularly likely to have children if their relationship is basically sound but has become a little dull. If so, partners do not see having a child as a way to enhance their solidarity, but rather as providing a new challenge to their relationship. The negative effect of value consensus on the likelihood of higher-order births seems to fit this same interpretation. Parents who experience relatively little value consensus may see having additional children as a way to infuse their life with a new challenge.

This interpretation of having children as a way to infuse a relationship with a new challenge seems to hold for both first- and higher-order births. Apparently, the quality of their relationship is taken into account by couples both in deciding on entry into parenthood and in deciding on family expansion. In fact, the results for higher-order births are even more clear-cut. Having higher-order births is being postponed if a lot of negative interaction is going on in a relationship and if a relationship is characterized by a medium to high level of positive interaction. Combined with the negative effect of value consensus, this suggests that higherorder births are particularly likely among couples with a basically sound relationship, in which relatively little is going on among the partners, neither in the sense of communication nor in the sense of joint things in life to strive for.

A final surprising finding is our lack of evidence for an effect of separation proneness on childbearing rates, as this conflicts with the results of the study done by Myers (1997). One explanation could be that Myers used multiple indicators for separation proneness, including cognitive aspects and actions, whereas we used a one-item measure. Hence, we are cautious to conclude that there is no effect of 
separation proneness on fertility. Another explanation could be that the cultural setting in the Netherlands is different from that in the United States. Union dissolution rates are lower in the Netherlands than in the United States (UNECE 2005). As a result, couples in the Netherlands may be less occupied with the possibility of a future separation or divorce than couples in the United States and focus on the interaction processes within the relationship rather than on perceived union dissolution when deciding on childbearing.

Taken together, our results show that relationship quality influences the timing of childbearing within couple relationships. The issue of which dimensions of relationship quality have an effect was treated as exploratory. In addition, not all aspects of relationship quality were measured equally reliable. This makes it hard to find statistically significant effects. Therefore, the effects that we did find are probably quite robust. Nonetheless, replication of our results in other studies is desirable. What is also needed is the development and testing of more rigorous hypotheses about which aspects of relationship quality influence childbearing in which ways. Future research is also needed to redress other shortcomings of this study. For instance, our measure of the quality of the relationship was based on the report of one of the partners only. It might be that partners differ in their views on the quality of their relationship. In these circumstances, it would be interesting to have both partners' evaluations of the relationship, and to see whether the views of one of the partners are more important than those of the other. In addition, this study used a relatively short time-frame, making it hard to say whether relationship quality only effects the timing of childbearing, or whether it also influences total fertility. Finally, this study focused on relatively young couples and it might be that the influence of the quality of the relationship is partly dependent on the age of the couples involved. To answer these latter two questions, studies should follow couples during the whole of their reproductive life span.

Open Access This article is distributed under the terms of the Creative Commons Attribution Noncommercial License which permits any noncommercial use, distribution, and reproduction in any medium, provided the original author(s) and source are credited.

\section{References}

Amato, P. R., Johnson, D. R., Booth, A., \& Rogers, S. J. (2003). Continuity and change in marital quality between 1980 and 2000. Journal of Marriage and Family, 65, 1-22.

Baizán, P., Aassve, A., \& Billari, F. C. (2003). Cohabitation, marriage, and first birth: The interrelationship of family formation events in Spain. European Journal of Population, 19, 147-169.

Baizán, P., Aassve, A., \& Billari, F. C. (2004). The interrelations between cohabitation, marriage and first birth in Germany and Sweden. Population and Environment, 25, 531-561.

Becker, G. S., Landes, E. M., \& Michael, R. T. (1977). An economic analysis of marital instability. Journal of Political Economy, 85, 1141-1187.

Blossfeld H. P. (Ed.). (1995). The new role of women. Family formation in modern societies. Boulder, CO: Westview.

Bulatao, R. A. (1981). Values and disvalues of children in successive childbearing decisions. Demography, 18, 1-25.

Buunk, B., \& Nijskens, J. (1980). Communicatie en satisfactie in intieme relaties. [Communication and satisfaction in intimate relationships]. Gedrag, 4, 240-260. 
Callan, V. J. (1985). Comparisons of mothers of one child by choice with mothers wanting a second birth. Journal of Marriage and the Family, 47, 155-164.

Callan, V. J. (1986). The impact of the first birth: Married and single women preferring childlessness, one child, or two children. Journal of Marriage and the Family, 48, 261-269.

Carlson, M. J. ( 2007). Trajectories of couple relationship quality after childbirth: Does marriage matter? Working paper 897, Princeton University, Woodrow Wilson School of Public and International Affairs, Center for Research on Child Wellbeing.

Cherlin, A. (1977). The effect of children on marital dissolution. Demography, 14, 265-272.

Cohen, S. B., \& Sweet, J. A. (1974). The impact of marital disruption and remarriage on fertility. Journal of Marriage and the Family, 36, 87-96.

Coombs, L. C., \& Chang, M. (1981). Do husbands and wives agree? Fertility attitudes and later behavior. Population and Environment, 4, 109-127.

Corijn, M., Liefbroer, A. C., \& De Jong Gierveld, J. (1996). It takes two to tango, doesn't it? The influence of couple characteristics on the timing of the birth of the first child. Journal of Marriage and the Family, 58, 117-126.

De Leeuw, E. D., \& De Heer, W. (2001). Trends in household survey nonresponse: A longitudinal, international comparison. In R. M. Groves, D. A. Dillman, J. L. Eltinge, \& R. J. A. Little (Eds.), Survey nonresponse (pp. 41-54). New York: Wiley.

Fawcett, J. T. (1988). The value of children and the transition to parenthood. Marriage and Family Review, 12, 11-34.

Friedman, D., Hechter, M., \& Kanazawa, S. (1994). A theory of the value of children. Demography, 31, 375-401.

Giddens, A. (1991). Modernity and self-identity. Self and society in the late modern age. Cambridge: Polity Press.

Glenn, N. D., \& McLanahan, S. (1982). Children and marital happiness: A further specification of the relationship. Journal of Marriage and the Family, 62, 927-947.

Glenn, N. D. (1989). Duration of marriage, family composition and marital happiness. National Journal of Sociology, 3, 3-24.

Glenn, N. D. (1990). Quantitative research on marital quality in the 1980s: A critical review. Journal of Marriage and the Family, 52, 818-831.

Helms-Erickson, H. (2001). Marital quality ten years after the transition to parenthood: Implications of the timing of parenthood and the division of housework. Journal of Marriage and Family, 63, 10991110 .

Inglehart, R., \& Baker, W. E. (2000). Modernization, cultural change, and the persistence of traditional values. American Sociological Review, 65, 19-51.

Jansen, M. D., \& Liefbroer, A. C. (2006). Couples' attitudes, childbirth and the division of labor. Journal of Family Issues, 27, 1487-1511.

Johnson, D. R., White, L. K., Edwards, J. N., \& Booth, A. (1986). Dimensions of marital quality: Towards methodological and conceptual refinement. Journal of Family Issues, 71, 31-49.

Koo, H. P., \& Janowitz, B. K. (1983). Interrelationships between fertility and marital dissolution: Results of a simultaneous logit model. Demography, 20, 129-145.

Kurdek, L. A. (1999). The nature and predictors of the trajectory of change in marital quality for husbands and wives over the first 10 years of marriage. Developmental Psychology, 35, 1283-1296.

Liefbroer, A. C., \& Kalmijn, M. (1997). Panel Study of Social Integration in the Netherlands 1987-1995 (PSIN8795). Codebook. Unpublished manuscript. The Netherlands: Interuniversity Center for Social Science Theory and Methodology, Utrecht University.

Lillard, L. A., \& Waite, J. L. (1993). A joint model of marital childbearing and marital disruption. Demography, 30, 653-681.

Miller, W. B., \& Pasta, D. J. (1994). The psychology of child timing: A measurement instrument and a model. Journal of Applied Social Psychology, 24, 218-250.

Morgan, S. P. (1985). Individual and couple intentions for more children: A research note. Demography, 22, 125-132.

Myers, S. M. (1997). Marital uncertainty and childbearing. Social Forces, 75, 1271-1289.

Norton, R. (1983). Measuring marital quality: A critical look at the dependent variable. Journal of Marriage and the Family, 45, 141-151.

Schoen, R., Astone, N. M., Kim, Y. J., Nathanson, C. A., \& Fields, J. M. (1999). Do fertility intentions affect fertility behaviour? Journal of Marriage and the Family, 61, 790-799. 
Spanier, G. B. (1976). Measuring dyadic adjustment: New scales for assessing the quality of similar dyads. Journal of Marriage and the Family, 38, 15-28.

StataCorp (2005). Stata Statistical Software: Release: 09. College Station, TX: Stata Corporation.

Thomson, E. (1997). Couple childbearing desires, intentions, and births. Demography, 34, 343-354.

Thomson, E. (2002). Motherhood, fatherhood and family values. In R. Lesthaeghe (Ed.), Meaning and choice: Value orientations and life course decisions (pp. 251-272). The Hague/Brussels: Nidi/ CBGS publications.

Thomson, E., \& Henz, U. (2005). Union stability and stepfamily fertility in Austria, Finland, France \& West Germany. European Journal of Population, 21, 3-29.

Thomson, E., \& Hoem, J. (1998). Couple childbearing plans and births in Sweden. Demography, 35, 315322.

Thomson, E., McDonald, E., \& Bumpass, L. (1990). Fertility desires and fertility: Hers, his, and theirs. Demography, 27, 579-588.

Thornton, A. (1977). Children and marital stability. Journal of Marriage and the Family, 39, 531-540.

Thornton, A. (1978). Marital dissolution, remarriage, and childbearing. Demography, 15, 361-380.

UNECE (2005). Trends in Europe and North America. Geneva: United Nations Economic Commission for Europe.

Waite, L. J., \& Lillard, L. A. (1991). Children and marital disruption. Journal of Sociology, 96, 19301953.

Wu, Z. (1996). Childbearing in cohabitational relationships. Journal of Marriage and the Family, 58, 281-292.

Xu, X. (1998). Marital quality revisited: A replication and extension of the JWEB model. Sociological Spectrum, 18, 367-382. 